\title{
A Long-term Estrogen Deficiency in Ovariectomized Mice is Associated with Disturbances in Fatty Acid Oxidation and Oxidative Stress
}

\section{Deficiência de estrogênio em longo prazo em camundongas ovarietcomizadas está associada a distúrbios na oxidação de ácidos graxos e estresse oxidativo}

\author{
Monique Cristine de Oliveira ${ }^{1,2}$ Lilian Brites Campos-Shimada ${ }^{1} \quad$ Maria Raquel Marçal-Natali ${ }^{1}$ \\ Emy Luiza Ishii-Iwamoto ${ }^{1}$ Clairce Luzia Salgueiro-Pagadigorria ${ }^{1}$ \\ 1 Universidade de Maringá, Maringá, PR, Brazil \\ ${ }^{2}$ Centro Universitário de Ingá, Maringá, PR, Brazil \\ Address for correspondence Monique Cristine de Oliveira, Centro \\ Universitário de Ingá, Rod. PR 317, 6114, Parque Industrial, 200, \\ Maringá, PR, 87035-510, Brazil \\ Rev Bras Ginecol Obstet 2018;40:251-259. \\ (e-mail: prof.moniqueoliveira@uninga.edu.br).
}

\section{Abstract \\ Keywords \\ - mitochondria \\ - non-alcoholic fatty liver disease \\ - obesity \\ - ovariectomy \\ - reactive oxygen species}

\section{Resumo}

Objective The aim of this work was to evaluate the changes caused by estrogen deficiency in lipid metabolism.

Methods This study encompassed direct measurements of plasma biochemical analyses, liver lipid contents, and assessments of the mitochondrial $\beta$-oxidation capacity as well as an evaluation of the liver redox status in an animal model of estrogen deficiency.

Results When compared with control mice, the livers of ovariectomized (OVX) mice presented considerable accretions in their lipid contents, which were accompanied by increased levels of lipid peroxidation in liver homogenates and mitochondria from OVX groups and decreased reduced glutathione (GSH) contents. In isolated mitochondria, estrogen deficiency inhibited mitochondrial $\beta$-oxidation of fatty acids irrespective of their chain length. The liver mitochondrial and peroxisomal $\mathrm{H}_{2} \mathrm{O}_{2}$ generations in $\mathrm{OVX}$ mice were increased. Additionally, the activities of all antioxidant enzymes assessed were decreased.

Conclusion These data provide one potential explanation for the increased susceptibility to metabolic diseases observed after menopause.

Objetivo O objetivo desse trabalho foi avaliar as alterações causadas pela deficiência estrogênica no metabolismo de lipídeos.

Métodos Este estudo abrangeu análises bioquímicas plasmáticas, verificação de conteúdo lipídico do fígado e avaliações da capacidade de $\beta$-oxidação mitocondrial e do estado redox do fígado em um modelo animal de deficiência estrogênica. received

November 11, 2017

accepted

March 6, 2018
DOI https://doi.org/

10.1055/s-0038-1666856. ISSN 0100-7203.
Copyright @ 2018 by Thieme Revinter

Publicações Ltda, Rio de Janeiro, Brazil
License terms

(ㄷ) (i) $\ominus$ (5) 


\author{
Descritores \\ - mitocôndrias \\ - doença hepática \\ gordurosa não \\ alcoólica \\ - obesidade \\ - ovariectomia \\ - espécies reativas de \\ oxigênio
}

Resultados Os fígados das camundongas ovariectomizadas (OVXs) apresentaram acréscimos consideráveis no conteúdo de lipídeos, que foram acompanhados por aumento de peroxidação lipídica em homogenatos e mitocôndrias de fígado e diminuição do conteúdo de glutationa reduzida (GSH) quando comparadas as camundongas do grupo controle. Nas mitocôndrias isoladas, a deficiência estrogênica causou a inibição da $\beta$-oxidação mitocondrial independentemente do comprimento da cadeia dos ácidos graxos. A geração mitocondrial e peroxissomal de $\mathrm{H}_{2} \mathrm{O}_{2}$ apresentou-se aumentada em camundongas OVXs. Além disso, as atividades de todas as enzimas antioxidantes avaliadas foram diminuídas.

Conclusão Esses dados fornecem uma explicação potencial para o aumento da suscetibilidade às doenças metabólicas observadas após a menopausa.

\section{Introduction}

Menopause is associated with a higher incidence of metabolic syndrome (MS) and related comorbidities, including obesity, insulin resistance, type 2 diabetes, dyslipidemia and nonalcoholic fatty liver disease (NAFLD). ${ }^{1}$

The mechanisms involved in the pathogenesis of NAFLD and its progression to nonalcoholic steatohepatitis (NASH) have not been fully elucidated to date, but the most accepted is the "two-hit" hypothesis. ${ }^{2}$ According to this paradigm, the primary abnormality ("first hit") is most likely insulin resistance, which leads to the accumulation of triacylglycerols (TG) within the hepatocytes. Then, the oxidative stress established as a result of fat accumulation represents the "second hit," which induces hepatocyte injury and inflammation, both factors contributing to the progression of the disease.

Therefore, in postmenopausal women, the insulin resistance can arise as an important contributing factor to the development of NAFLD. Furthermore, through genomic actions, estrogen exerts important effects on the liver lipid metabolism, in such a way that in a condition of estrogen deficiency, the hepatic metabolism is diverted from lipid oxidation to fatty acid biosynthesis, thus favoring its esterification and accumulation as triacylglycerols (TGs) in the cytosol of hepatocytes. ${ }^{3}$ In fact, NAFLD has been demonstrated in animal models of estrogen deficiency ${ }^{3}$ and in postmenopausal women. $^{4}$

A question that arises is whether livers from OVX mice preserve the capacity of buffering fatty acids without metabolic disturbances even after a longer period of ovarian hormone production cessation, a condition corresponding to a postmenopausal period in women.

It has long been known that estrogen functions as an in vitro and in vivo antioxidant, and not only because of its phenolic chemical structure. In the liver, estrogen can bind to estrogen receptors ${ }^{5}$ and reduce the mitochondrial reactive oxygen species (ROS) generation. ${ }^{6,7}$ In addition, estrogen can up-regulate the nuclear expression and/or the activity ${ }^{6-8}$ of several antioxidant enzymes. Thus, in a condition of estrogen deficiency, an oxidative status could arise as result of higher ROS generation by mitochondria and/or peroxisomes, or decrease in the effectiveness of antioxidant systems, or both. This could play a crucial role in the pathogenesis of a wide range of chronic and degenerative disorders (aging, atherosclerosis, neurodegeneration, cancer, cataract) as well as in acute clinical conditions. ${ }^{9}$

In this way, this work was planned to investigate the changes of the liver mitochondrial oxidation and liver redox status in an animal model of estrogen deficiency. The OVX mice constitute a very suitable model of estrogen deficiency, which is why they were used in this work. This could be helpful to a better understanding of the pathogenesis of diseases as well as to open new perspectives for therapeutic approaches targeting these antioxidant enzymes.

\section{Methods}

\section{Material}

Substrates adenosine triphosphate (ATP), adenosine diphosphate (ADP), phenylmethylsulfonyl fluoride (PMSF), 0 -phthalaldehyde (OPA), horseradish peroxidase, 2',7'-dichlorofluorescein diacetate (DCFH-DA), 2',7'-dichlorofluorescein (DCF), reduced glutathione (GSH) and oxidized glutathione (GSSG) were purchased from Sigma Chemical Co. (St. Louis, MO, USA).

\section{Animals}

Female Swiss CD1 mice weighing 25-30 g (7 weeks of age) were randomly assigned to sham-operation (SHAM/control) or bilateral ovariectomy. For surgery, the mice were anesthetized with a mixture of ketamine-xylazine $(50-10 \mathrm{mg} / \mathrm{kg}$, intraperitoneal [IP].), and their body weight was monitored each week. The mice were fed ad libitum with a standard laboratory diet (Nuvilab, São Paulo, SP, Brazil) for 10 weeks. All procedures performed in this study were conducted in strict adherence to the guidelines of the Ethics Committee for Animal Experimentation of the University of Maringá (079/2008).

\section{Analysis of Serum Lipid Profile and Glycemia}

The mice were fasted for $12 \mathrm{~h}$ and the blood was collected by cardiac puncture. Plasma glucose concentrations were determined using a glucose analyzer (Optium). Total cholesterol and triacylglycerols (TGs) were analyzed by standard methods (Gold Analisa Diagnóstica Ltda., Belo Horizonte, MG, Brazil). Very low-density lipoprotein (VLDL) cholesterol was calculated 
from TG levels (Friedewald equation) and low-density lipoprotein (LDL) cholesterol was determined by subtracting highdensity lipoprotein (HDL) and VLDL from the total cholesterol.

\section{Liver Determination of the Total Lipid Content}

The total lipid content of the liver was measured by gravimetry and expressed in grams per $100 \mathrm{~g}$ of wet liver weight following the method described by Folch et al. ${ }^{10}$

\section{Isolation of Mitochondria and Peroxisomes}

Mitochondria and peroxisomes from female mice livers were isolated by differential centrifugation according to Bracht et al $^{11}$ and Natarajan et al, ${ }^{12}$ respectively.

\section{Determination of Protein Contents}

Protein contents of the mitochondrial, peroxisomes and homogenate suspensions were measured using the method of Lowry et $\mathrm{al}^{13}$ and using bovine serum albumin as a standard.

\section{Determination of Oxygen Uptake by Isolated Mitochondria Oxidizing Fatty Acids}

Oxygen uptake by intact mitochondria was determined polarographically. The reaction was initiated by the addition of (a) $20 \mu \mathrm{M}$ palmitoyl-L-carnitine, (b) $20 \mu \mathrm{M}$ palmitoyl-CoA $+2.0 \mathrm{mM}$ L-carnitine, or (c) $20 \mu \mathrm{M}$ octanoyl-CoA $+2.0 \mathrm{mM}$ L-carnitine to mitochondrial suspensions $(0.6-1.2 \mathrm{mg} / \mathrm{ml}) .^{14}$

\section{Membrane-bound Enzymatic Activities}

Freeze-thawing disrupted mitochondria were used as enzymes sources to evaluate the membrane-bound enzymatic activities. Nicotinamide adenine dinucleotide plus hydrogen (NADH)-oxidase and succinate-oxidase activities were assayed polarographically. ${ }^{11}$

\section{Liver Perfusion Experiments}

The non-recirculating perfusion technique with Krebs-Henseleit-bicarbonate buffer described by Scholz and Bucher ${ }^{15}$ was used. For the surgical procedure, the animals were anesthetized by IP injection of ketamine-xylazine (50-10 $\mathrm{mg} / \mathrm{kg}$ ). The perfusion flow was constant in each individual experiment, and it was adjusted to $10 \mathrm{ml} / \mathrm{min}$ depending on the liver weight. The livers of 24-hour fasted mice were used for the measurement of fatty acid oxidation. A mixture of octanoate $(0.3 \mathrm{mM})$ plus $\left[1-{ }^{14} \mathrm{C}\right]$ octanoate $(0.01 \mu \mathrm{Ci} / \mathrm{ml})$ and $50 \mu \mathrm{M}$ fatty acid-free bovine serum albumin was dissolved in the perfused fluid.

\section{Analytical}

The oxygen concentration in the venous perfusate was continuously monitored with a Teflon-shielded platinum electrode. $\beta$-hydroxybutyrate and acetoacetate were measured by standard enzymatic procedures. ${ }^{16}$ The carbon dioxide production was measured by trapping ${ }^{14} \mathrm{CO}_{2}$ in phenylethylamine. The radioactivity was measured by liquid scintillation spectroscopy. The following liquid scintillation solution was used: toluene/ethanol (2/1) containing $5 \mathrm{~g} / \mathrm{L}$ of 2.5-diphenyloxazole (PPO) and $0.15 \mathrm{~g} / \mathrm{L}$ of 2.2-p-phenylene- bis (5-phenyloxazole) (POPOP). Metabolic rates were calculated from input-output differences and the total flow rates were referred to the weight of the liver.

\section{Determination of Reduced Glutathione (GSH) and Malondialdehyde (MDA) Contents}

The GSH and MDA levels were measured in liver homogenates and isolated mitochondria. To prepare the homogenates, samples of the livers were freeze-clamped with liquid nitrogen and homogenized in a cold medium containing $250 \mathrm{mM}$ of sucrose, $1 \mathrm{mM}$ of ethylene glycol tetraacetic acid (EGTA) and hydroxyethyl piperazine ethanesulfonic (HEPES) 10 mM pH 7.2 using a Van-Potter homogenizer $(1: 4, \mathrm{w}: \mathrm{v})$.

The GSH levels were determined fluorimetrically, according the method described by Hissin and Hilf. ${ }^{17}$ The results were expressed as $\mu \mathrm{g} \mathrm{GSH} / \mathrm{mg}$ protein present in the supernatant. The MDA concentrations were measured by direct spectrophotometry, using the thiobarbituric acid reactive substances(TBARS) method, considered a biomarker of lipid peroxidation and oxidative stress. ${ }^{18}$ The results were expressed as nmol MDA/mg protein using a molar extinction coefficient for MDA of $1.56 \times 10^{5} \mathrm{M}^{-1} \times \mathrm{cm}^{-1}$.

\section{Determination of Mitochondrial Hydrogen Peroxide $\left(\mathrm{H}_{2} \mathbf{O}_{2}\right)$ Generation}

The mitochondrial $\mathrm{H}_{2} \mathrm{O}_{2}$ formation was monitored with 2',7'dichlorofluorescein diacetate (DCFH-DA). The results were expressed as pmol dichlorofluorescein (DCF) produced/min/ mg protein. ${ }^{19}$

\section{Determination of Peroxisomal Hydrogen Peroxide $\left(\mathrm{H}_{2} \mathrm{O}_{2}\right)$ Generation}

The $\mathrm{H}_{2} \mathrm{O}_{2}$ generated by the peroxisomal oxidation of palmitoyl-CoA was measured fluorimetrically. ${ }^{20}$ The results were expressed as pmol of DCF produced $/ \mathrm{min} / \mathrm{mg}$ protein.

\section{Determination of Antioxidant Enzymes Activities}

The chymotrypsin (CT) activity in the peroxisomal factions was assayed spectrophotometrically, according to Aebi. ${ }^{21}$ The enzymatic activity was expressed as $\mu \mathrm{mol} \mathrm{H}_{2} \mathrm{O}_{2}$ reduced $/ \mathrm{min} / \mathrm{mg}$ of peroxisomal protein using the coefficient of molar extinction of $\mathrm{H}_{2} \mathrm{O}_{2}$ of $0.036 \mathrm{mM}^{-1} \times \mathrm{cm}^{-1}$.

The activities of the other antioxidant enzymes (cytosolic superoxide dismutase [SOD1], glutathione peroxidase [GSHPx], Glutathione reductase [GSSG-Red] and glucose-6-phosphate dehydrogenase activity [G6PD]) were measured in homogenates, using the Dounce homogenizer, prepared from livers of overnight fasted mice. The activity of the antioxidant enzymes was determined in the supernatant after a $30,000 \times g$ centrifugation, for 10 minutes. In the case of superoxide dismutase (SOD), in addition to the SOD1, the mitochondrial SOD (SOD2) activity was assessed in the supernatant $(6,000 \times g)$ of sonicated mitochondrial fractions. The procedure described below was adopted for both.

Superoxide dismutase: The SOD activities were determined, ${ }^{22}$ and the enzymatic activity was expressed as $U$ of superoxide dismutase/mg protein 
Glutathione peroxidase: The glutathione peroxidase activity was measured according to Paglia and Valentine. ${ }^{23}$ The enzymatic activity was expressed as nmol of NADPH oxidized/min $\times$ mg protein using the molar extinction coefficient, $\varepsilon=6.22 \mathrm{mM}^{-1} \times \mathrm{cm}^{-1}$.

Glutathione reductase: Glutathione reductase activity was determined according to Mize and Langdon. ${ }^{24}$ The enzymatic activity was calculated as nmol of NADPH oxidized/min $\times$ mg protein.

Glucose-6-phosphate dehydrogenase activity: The G6PD activity was determined spectrophotometrically. ${ }^{25}$ To obtain the accurate enzyme activities for G6PD and PGD, both PGD activity alone and total dehydrogenase activity (G6PD + PGD) were measured. The G6PD activity was expressed as nmol of NADPH produced/min $\times$ mg protein using the molar extinction coefficient, $\varepsilon=6.22 \mathrm{mM}^{-1} \times \mathrm{cm}^{-1}$.

\section{Treatment of Data}

The data in the figures and tables are expressed as means \pm standard error (SEM). The significant differences among the means were identified by the Student t-test and two-way analysis of variance (ANOVA) followed by a Newman-Keuls posttest. The results are given in the text as probability values $(P)$. A $p$-value $<0.05$ was adopted as a criterion of significance. The statistical analysis was performed by means of GraphPAD Software programs (GraphPAD Software, La Jolla, CA, USA).

\section{Results}

Body Weight and Fasting Plasma and Serum Profiles As confirmation of successful ovariectomy-induced suppression of endogenous estrogen production, at 10 weeks after operation, the OVX mice exhibited an evident uterine atrophy, with uterine/BW ratios 4 times minor than SHAM operated animals (placebo surgery) (-Table $\mathbf{1}$ ). In the OVX mice, the body weight was also $42.5 \%$ higher, and this was accompanied by increased adiposity, as can be seen by the differences in the periuterine adipose tissue (PUAT) to body weight ratios of these animals ( $+109 \%$ ). The liver to body weight ratio was also

Table 1 Body weight and tissue weight changes of female SHAM and ovariectomized mice 10 weeks after operation

\begin{tabular}{|l|l|l|}
\hline Variable & SHAM $(\boldsymbol{n}=6)$ & OVX $(\boldsymbol{n}=6)$ \\
\hline Glucose $(\mathrm{mmol} / \mathrm{L})$ & $4.79 \pm 0.27$ & $6.30 \pm 0.71^{*}$ \\
\hline Total cholesterol $(\mathrm{mmol} / \mathrm{L})$ & $2.93 \pm 0.30$ & $5.83 \pm 0.65^{*}$ \\
\hline $\mathrm{HDL}$ cholesterol $(\mathrm{mmol} / \mathrm{L})$ & $1.53 \pm 0.33$ & $1.83 \pm 0.23$ \\
\hline $\mathrm{LDL}$ cholesterol $(\mathrm{mmol} / \mathrm{L})$ & $1.29 \pm 0.21$ & $3.88 \pm 0.63^{*}$ \\
\hline VLDL cholesterol $(\mathrm{mmol} / \mathrm{L})$ & $0.11 \pm 0.04$ & $0.12 \pm 0.03$ \\
\hline Triacylglycerols $(\mathrm{mmol} / \mathrm{L})$ & $0.56 \pm 0.19$ & $0.63 \pm 0.16$ \\
\hline Liver total lipid content $(\%)$ & $5.59 \pm 0.78$ & $8.06 \pm 0.48^{*}$ \\
\hline
\end{tabular}

Abbreviations: HDL, high-density lipoprotein; LDLD, low-density lipoprotein; VLDL, very low-density lipoprotein; OVX, ovariectomized Values are means \pm standard error of the mean (SEM).

${ }^{*} p<0.05$ compared with SHAM values as identified by Student t-test.
Table 2 Physiological measurements of female SHAM and ovariectomized mice 10 weeks after operation

\begin{tabular}{|l|l|l|}
\hline Variable & SHAM $(\boldsymbol{n}=15)$ & OVX $(\boldsymbol{n}=15)$ \\
\hline Body weight $(\mathrm{g})$ & $34.66 \pm 3.73$ & $49.40 \pm 3.39^{*}$ \\
\hline $\begin{array}{l}\text { Food intake } \\
(\mathrm{g} / \text { day/kg BW) }\end{array}$ & $186.485 \pm 21.77$ & $160.369 \pm 15.39$ \\
\hline Uterus/BW (\%) & $0.39 \pm 0.07$ & $0.094 \pm 0.06^{*}$ \\
\hline Liver/BW (\%) & $3.30 \pm 0.23$ & $3.59 \pm 0.15$ \\
\hline PUAT/BW (\%) & $2.61 \pm 0.38$ & $5.46 \pm 0.90^{*}$ \\
\hline
\end{tabular}

Plasma measures of triglycerides, total cholesterol, HDL-cholesterol, LDL-cholesterol, VLDL-cholesterol and glucose from SHAM and OVX mice, fasted overnight, were analyzed by standard methods as described in the section of Materials and Methods. Liver fragments from the SHAM and OVX mice were homogenized in a 2:1 chloroformmethanol mixture to determine the liver total lipid contents by gravimetric analyses. Values are means \pm standard error of the mean (SEM). ${ }^{*} p<0.05$ compared with SHAM values as identified by the Student t-test

8.7\% higher in OVX mice. This result was corroborated by the quantification of the total liver lipid content by gravimetry. - Table 2 depicts the plasma dosages of these animals. Although no differences have been noted in the food intake between these two animal groups (-Table 2), the fasting plasma glucose levels were significantly elevated in the OVX mice, as well as the total cholesterol and LDL cholesterol levels (- Table 2). Average fasting TGs, HDL and VLDL cholesterol levels were not significantly different between the groups. Total lipids contents were also evaluated ( $\mathbf{- T a b l e ~} \mathbf{2}$ ). Although livers from control groups exhibited normal total lipid content of $\sim 5.8 \%,{ }^{26}$ the livers from OVX mice presented significantly higher lipid contents $(+61 \%)$, characterizing extensive hepatic steatosis.

\section{Effects of Estrogen Deficiency in Isolated Mitochondria}

To evaluate the effects of estrogen deficiency on mitochondrial $\beta$-oxidation of fatty acids, the medium chain fatty acid octanoate and long-chain fatty acid palmitate were used. In this series, these fatty acids were utilized as acyl CoA derivatives (octanoyl-CoA, palmitoyl-CoA) in the presence of carnitine, and in another series, palmitoyl-L-carnitine was used. The oxygen uptake due to oxidation of these substrates was measured in the presence of 2,4-dinitrophenol (DNP); under these conditions, the rate of $\beta$-oxidation occurs at its maximum speed. Thus, the effects of estrogen deficiency on fatty acid transport and the oxidizing capacity of intra-mitochondrial enzymes could be evaluated. - Fig. 1 shows that the $\beta$-oxidation was inhibited irrespective of the fatty acid used. The oxidation of octanoyl-CoA was inhibited in OVX mice by $56.2 \%$, and palmitoyl-CoA by $45.4 \%$, as well as palmitoyl-carnitine, whose oxidation was inhibited in OVX mice by $\sim 45 \%$.

The $\beta$-oxidation inhibition irrespective of the fatty acid used could be a result of alterations in the electron transport chain. In this way, the effects of estrogen deficiency on the activities of membrane-bound enzymes, NADH-oxidase and succinate-oxidase were analyzed. However, the activities of 


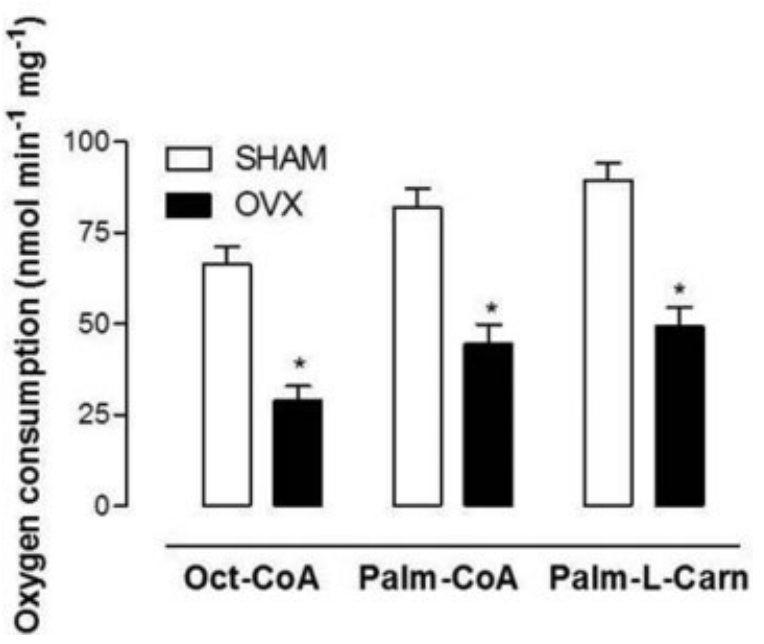

Fig. 1 Oxygen uptake due to fatty acid oxidation in intact mitochondria uncoupled with 2,4-dinitrophenol (DNP). The oxidation of fatty acids was measured polarographically in an incubation medium, in the presence of DNP. The reaction was initiated by the addition of palmitoyl-L-carnitine, palmitoyl-CoA + L-carnitine, or octanoyl-CoA + L-carnitine. The vertical bars represent standard errors of the mean. The asterisks indicate significant differences between the groups, SHAM $(n=6)$ and ovariectomized (OVX) $(n=6)$, as revealed by analysis of variance with Student t-test set at ${ }^{*} p<0.05$.

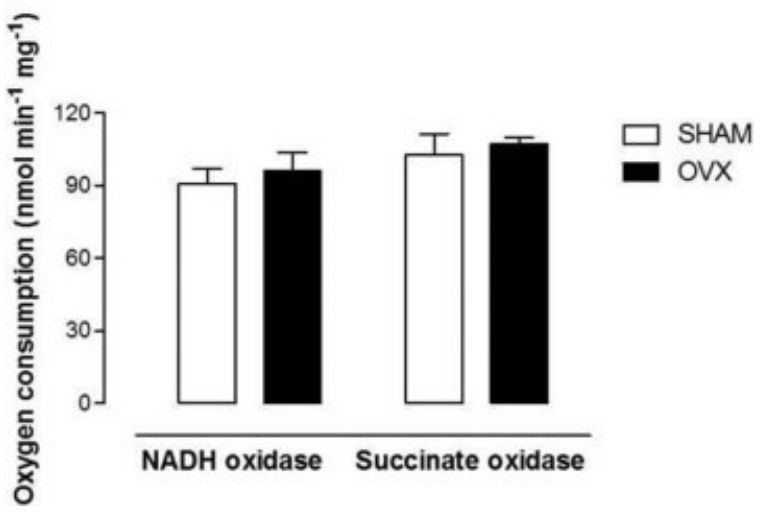

Fig. 2 Nonalcoholic steatohepatitis (NADH)-oxidase and succinateoxidase activities in freeze-thawing disrupted mitochondria. The vertical bars represent standard errors of the mean. The asterisks indicate significant differences between the values in SHAM $(n=8)$ and ovariectomized (OVX) $(n=8)$ conditions as revealed by analysis of variance with Student t-test set at ${ }^{*} p<0.05$.

these enzymes were unaffected in the livers of OVX mice. So, the reduction in the mitochondrial $\beta$-oxidation capacity could not be secondary to an inhibition in the respiratory chain (-Fig. 2).

\section{Oxygen Uptake, ${ }^{14} \mathrm{CO}_{2}$ Production and Ketogenesis in the Liver of Fasted Mice}

To determine whether the changes observed on mitochondrial functions were reproduced in intact livers, metabolic fluxes due to exogenous octanoate oxidation were measured in livers from SHAM and OVX mice. In the effluent perfusion fluid, the levels of ketone bodies (acetoacetate and $\beta$-hydroxybutyrate), $\mathrm{CO}_{2}$ pro-
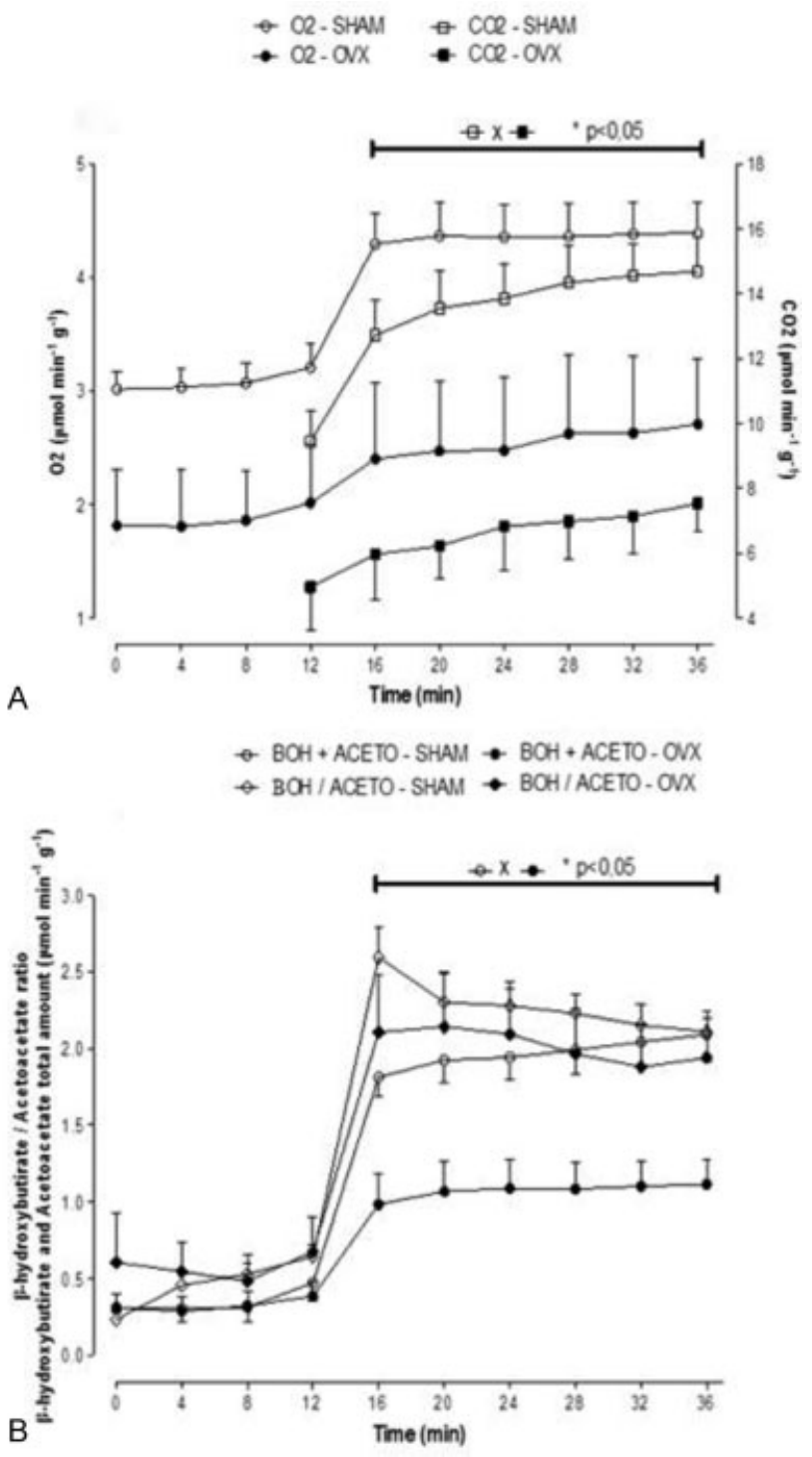

Fig. 3 Time course of the changes in metabolic flux due to oxidation of octanoate in perfused livers from fasted mice. $0.3 \mathrm{mM}$ octanoate, $\left[1-{ }^{14} \mathrm{C}\right.$ ]octanoate $(0.01 \mu \mathrm{Ci} / \mathrm{ml})$ plus $50 \mu \mathrm{M}$ fatty acid-free bovine serum albumin were infused at 12-36 min of perfusion. Oxygen uptake and ${ }^{14} \mathrm{CO}_{2}$ production (panel $\mathrm{A}$ ) and $\beta$-hydroxybutyrate and acetoacetate production (panel $B$ ) are reduced in the ovariectomized group $(n=4)$ compared with SHAM group $(n=4)$. Vertical bars represent mean standard errors. Asterisks indicate significant differences between the values as revealed by variance analysis with post hoc Newman-Keuls testing $(p<0.05)$.

duction and oxygen uptake due to octanoate oxidation were measured. -Fig. 3 illustrates the time course of these experiments. After the stabilization of oxygen uptake, samples of the outflowing perfusate were collected for the measurement of acetoacetate and $\beta$-hydroxybutyrate. After a period of 12 minutes, the livers were perfused with $0.3 \mathrm{mM}$ of octanoate plus $\left[1-{ }^{14} \mathrm{C}\right]$ octanoate $(0.01 \mu \mathrm{Ci} / \mathrm{ml})$ and $50 \mu \mathrm{M}$ of fatty acid-free bovine serum albumin for 24 minutes. The onset of octanoate infusion caused increases in oxygen uptake, $\beta$-hydroxybutyrate, acetoacetate and ${ }^{14} \mathrm{CO}_{2}$ production.

- Fig. 3A shows that oxygen uptake and ${ }^{14} \mathrm{CO}_{2}$ production were decreased in OVX mice. At minute 36 , the oxygen 
Table 3 Reduced glutathione and malondialdehyde contents

\begin{tabular}{|l|l|l|}
\hline Variable & SHAM $(\boldsymbol{n}=5)$ & OVX $(\boldsymbol{n}=5)$ \\
\hline Homogenate GSH & $3.19 \pm 0.24$ & $1.59 \pm 0.64^{* * *}$ \\
\hline Mitochondrial GSH & $0.94 \pm 0.02$ & $0.74 \pm 0.03^{* *}$ \\
\hline Homogenate MDA & $4.03 \pm 0.23$ & $14.08 \pm 1.89^{* * *}$ \\
\hline Mitochondrial MDA & $1.50 \pm 0.15$ & $4.29 \pm 0.45^{* * *}$ \\
\hline
\end{tabular}

Abbreviations: GSH, reduced glutathione; MDA, malondialdehyde; OVX, ovariectomized.

Reduced GSH and MDA contents are expressed as means \pm standard error of the mean (SEM) $(\mu \mathrm{g} \mathrm{GSH} / \mathrm{mg}$ protein or $\mathrm{nmol} \mathrm{MDA} / \mathrm{mg}$ protein, respectively).

${ }^{* *} p<0.01 ;{ }^{* * *} p<0.001$ vs the control. Asterisks indicate significant differences between the groups as revealed by Student t-test.

consumption of OVX mice were reduced by $38.5 \%$, and the ${ }^{14} \mathrm{CO}_{2}$ production of this group was decreased by $48.7 \%$ when compared with SHAM mice. The production of $\beta$-hydroxybutyrate and acetoacetate was also reduced; the OVX mice presented a reduction of $46.8 \%$ in the total amount of $\beta$-hydroxybutyrate and acetoacetate ( - Fig. 3B).

\section{General Liver Redox State}

In - Table 3, the total and mitochondrial GSH and MDA contents from these animals are also presented. from the livers of OVX mice exhibited total GSH contents $50 \%$ lower than those found in the control mice. Similarly, in the isolated mitochondria, the GSH content also was significantly lower in the OVX group (-21\%). As expected, the MDA contents were extensively increased in homogenate and mitochondria from OVX mice by $250 \%$ and $186 \%$, respectively.

\section{Mitochondrial and Peroxisomal $\mathrm{H}_{2} \mathrm{O}_{2}$ Generation}

The results of the experiments of measurements of $\mathrm{H}_{2} \mathrm{O}_{2}$ production by isolated liver mitochondria and peroxisomes of OVX and control mice are presented in - Fig. 4 . As it can be

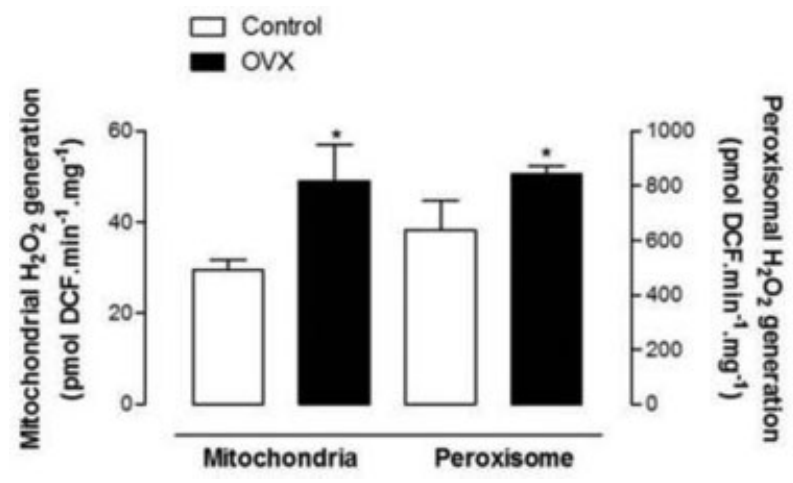

Fig. 4 Mitochondrial and peroxisomal hydrogen peroxide $\left(\mathrm{H}_{2} \mathrm{O}_{2}\right)$ generation. Mitochondrial and peroxisomal $\mathrm{H}_{2} \mathrm{O}_{2}$ generation from SHAM $(n=6)$ and $\operatorname{OVX}(n=6)$ mice was measured fluorometrically. The results are expressed as pmol 2,4-dinitrophenol (DCF) produced/min $\times$ mg protein. The results are means \pm standard error of the mean (SEM) and asterisks indicate significant differences between the groups as revealed by analysis of variance with Student $t$-test set at ${ }^{*} p<0.05$.
Table 4 Antioxidant enzyme activities

\begin{tabular}{|l|l|l|}
\hline $\begin{array}{l}\text { Antioxidant Enzyme } \\
\text { (per mg protein) }\end{array}$ & $\begin{array}{l}\text { SHAM } \\
(\boldsymbol{n}=6)\end{array}$ & $\begin{array}{l}\text { OVX } \\
(\boldsymbol{n}=6)\end{array}$ \\
\hline SOD1 $(\mathrm{U})$ & $1.20 \pm 0.22$ & $0.80 \pm 0.17^{*}$ \\
\hline SOD2 $(\mathrm{U})$ & $1.57 \pm 0.13$ & $0.92 \pm 0.07^{* * *}$ \\
\hline CT $(\mu \mathrm{mol} / \mathrm{min})$ & $18.35 \pm 1.26$ & $10.7 \pm 0.92^{* *}$ \\
\hline GSSG-Red $(\mathrm{nmol} / \mathrm{min})$ & $53.4 \pm 4.29$ & $32.55 \pm 2.86^{* *}$ \\
\hline GSH-Px $(\mathrm{nmol} / \mathrm{min})$ & $173.4 \pm 14.51$ & $293.15 \pm 30.62^{*}$ \\
\hline G6PD $(\mathrm{nmol} / \mathrm{min})$ & $6.18 \pm 0.56$ & $4.15 \pm 0.48^{*}$ \\
\hline
\end{tabular}

Abbreviations: CT, chymotrypsin; G6PD, glucose-6-phosphate dehydrogenase activity; GSH-Px, glutathione peroxidase; GSSG-Red, glutathione reductase; OVX, ovariectomized; SOD1, cytosolic superoxidase dismutase; SOD2, mitochondrial superoxidase dismutase. The results represent the means \pm standard error of the mean (SEM). ${ }^{*} p<0.05 ;{ }^{* *} p<0.01 ;{ }^{* * *} p<0.001$ vs the control.

Asterisks indicate significant differences between the groups as revealed by the Student t-test.

seen, the mitochondrial $\mathrm{H}_{2} \mathrm{O}_{2}$ generation was $\sim 68 \%$ higher in OVX mice than in the control group. Similarly, the peroxisomal $\mathrm{H}_{2} \mathrm{O}_{2}$ production, during the oxidation of palmitoyl-CoA, was significantly higher in OVX mice, by $14 \%$, as compared with the control group.

\section{Antioxidant Enzyme Activities}

Considering the high levels of lipoperoxidation and the restricted GSH levels found in the livers of OVX mice, the activity of several antioxidant enzymes was also evaluated, and the results are presented in -Table 4 .

First, the activities of cytosolic and mitochondrial SOD (SOD1 and SOD2, respectively) were assessed in the livers of OVX and control mice. This enzyme serves as a first antioxidant defense in the cell by catalyzing the dismutation of superoxide anions to hydrogen peroxide. When compared with the control group, the activities of SOD1 and SOD2 in OVX mice were reduced significantly, by $33 \%$ and $41 \%$, respectively.

The peroxisomal CT activity was reduced by $\sim 42 \%$ in the OVX group as compared with the control mice. The activity of another $\mathrm{H}_{2} \mathrm{O}_{2}$-scavenger enzyme, GSH-Px, exhibited a significant increase in the livers of OVX mice, of $\sim 40 \%$. The activities of the two enzymes responsible for restoring the GSH system, GSSG-Red and G6PD, are also presented in - Table 4. As it can be seen, the activities of these enzymes were reduced in the livers of OVX mice by $40 \%$ and $33 \%$, respectively, as compared with the control group.

\section{Discussion}

The results of the present study revealed that OVX mice fed with a standard diet during 10 weeks after the surgery reproduce a situation comparable to a physiological state of menopause that occurs in women in midlife. The levels of total cholesterol and LDL-cholesterol were higher in the OVX mice than in the SHAM mice, and these animals also exhibited increased body weight and adiposity, features that are reported in both women and in rodents with estrogen 
deficiency. ${ }^{26-29}$ The increased body weight could be a result of reduced energy expenditure. Rogers et al $^{30}$ demonstrated that loss of ovarian function in mice after 12 weeks of ovariectomy decreases energy expenditure and promotes less spontaneous physical activity during the dark phase. Oliveira et $\mathrm{al}^{29}$ also revealed decreased energy expenditure during light and dark periods in mice after five weeks of ovariectomy associated with a high-fat diet.

As expected and demonstrated in the literature, ${ }^{28}$ the livers of OVX animals exhibited a higher content of lipids than the mice from the SHAM group, which was confirmed by gravimetry measurements. This lipid accumulation could be the result of several factors, such as excessive food intake, alterations in the uptake or exportation of fatty acids, changes in mitochondrial oxidation of fatty acids and a reduction in the export of TGs. The average daily intake of food was not different between the SHAM and OVX groups. In fact, the normalization of the data by expressing food intake per $\mathrm{kg}$ of body weight revealed that OVX mice ingested lower amounts of food than SHAM mice, indicating that lipid accumulation in OVX mice is not a result of hyperphagia. This result also corroborates with the literature, $27,28,30,31$ in which authors found that OVX mice gained more weight than SHAM mice despite eating similar amounts of food, indicating an increased propensity to store energy as body weight.

The livers of OVX mice that were fed a standard diet for 10 weeks presented a clear modification in the fatty acid oxidative capacity. When compared with the mitochondria isolated from the SHAM group, fatty acid oxidation was reduced irrespective of the chain length. Moreover, no differences were found in the degree of inhibition between the oxidation of the acyl- or carnityl derivatives of fatty acids. These results support the view that the inhibition of fatty acid oxidation is not due to an alteration in a distinct step of the $\beta$-oxidation of medium-chain and long-chain fatty acids. A reduction in a common step, namely the enzymes of mitochondrial $\beta$-oxidation, the citric acid cycle and the respiratory chain, seems to be, thus, a plausible explanation.

The lack of significant differences between the oxidation of NADH or succinate oxidation in mitochondria from the SHAM and OVX mice groups excluded the hypothesis of a reduced activity of the electron transport chain components from complexes I and II to IV as a contributing factor to the inhibition of fatty acid oxidation.

The experiments performed in the perfused livers show the metabolic fluxes due to exogenous fatty acid oxidation, and this can reveal more details not only of mitochondrial oxidation but of other metabolic pathways linked to fatty acid oxidation in intact cells. The reduction found in ${ }^{14} \mathrm{CO}_{2}$ production from $\left[1-{ }^{14} \mathrm{C}\right]$ octanoate indicated that the activity of the citric acid cycle due to oxidation of exogenous octanoate was decreased in the perfused livers of OVX mice. Under normal conditions, the rate of the citric acid cycle is strictly dependent on NADH reoxidation via the mitochondrial respiratory chain and, in accordance, a parallel decrease in the oxygen consumption by the livers of OVX mice was observed.

The finding that the production of ketone bodies was reduced without significant change in the $\beta$-hydroxybuty- rate/acetoacetate ratio in the perfused liver suggested that the reduced flow through citric acid cycle was not a consequence of an impairment of specific enzymes of the cycle. Usually, in this case, an increase in the ketone bodies production is observed, as the rate of ketone bodies production is dependent on the rates of acetyl-CoA oxidation in the citric acid cycle, being the latter saturated at a lower concentration of acetyl-CoA than that of ketone bodies production. ${ }^{32}$ A reduced production of acetyl-CoA derived from octanoate oxidation seems to be, thus, the most plausible explanation for the decrease in both ketogenesis and ${ }^{14} \mathrm{CO}_{2}$ production from $\left[1-{ }^{14} \mathrm{C}\right]$ octanoate in perfused livers.

Since the contribution of mitochondria to fatty acid oxidation is nearly $90 \%$ of the overall fatty acid oxidation in isolated hepatocytes, ${ }^{33}$ it seems, thus, reasonable to suggest that a reduced rate of mitochondrial $\beta$-oxidation has accounted for most of the changes found in the parameters of fatty acid oxidation measured in both isolated mitochondria and perfused rat liver.

The exact mechanisms by which the livers of OVX mice reduced their capacity of fatty acid oxidation after a prolonged time of estrogen deficiency cannot be inferred from these data. However, a response to the insulin resistance state is a possibility to be considered, since suppression of estrogen production has demonstrated to impair both insulin sensitivity and glucose metabolism. ${ }^{34}$ There is evidence that under insulin resistance condition, the hepatic fatty acid synthesis is usually activated, and mitochondrial $\beta$-oxidation of fatty acid oxidation is impaired. ${ }^{35}$

Even though the reduced mitochondrial fatty acid oxidative capacity may be a consequence of the insulin resistance state, it may be also an adaptive or protective mechanism of hepatocytes to steatosis. It should also be commented that the reduced fatty acid capacity is probably only one of the metabolic disturbances of the livers resulting from a longterm menopausal condition.

The results of the present study also show the suitability of the animal model to compare the redox alterations involved in the postmenopausal NAFLD in women. The fat liver accumulation in the OVX mice was associated with a general worsening of the liver redox status.

In this work, the mitochondrial and peroxisomal ROS generations, which contribute to the majority of cellular ROS, were evaluated. Both mitochondria and peroxisomes of OVX mice produced considerably larger amounts of ROS than control mice and this, per se, could produce an imbalance in the liver redox status. As mitochondria are the main targets of the harmful effects of these species, a vicious cycle is established and the more mitochondrial ROS generation, the more mitochondrial damage and ROS generation. $^{36}$

Besides the higher mitochondrial and peroxisomal ROS, the current study revealed that several antioxidant defenses against oxidative stress were impaired. The liver GSH contents of OVX mice were decreased both in cytosol and mitochondria and this was accompanied by an increase in the lipoperoxidation, indicating that some oxidative damage had already occurred. 
The activity of several antioxidant enzymes was also assessed in this work. The results revealed that both SOD1 and SOD2 had their activity reduced in OVX mice. This could be explained, at least in part, as a consequence of the reduction in the CT activity, also found in these animals. ${ }^{37}$

In this way, a decrease in $\mathrm{CT}$ activity may compromise the overall antioxidant enzyme defense system, since $\mathrm{H}_{2} \mathrm{O}_{2}$ is shown to be a potent inhibitor of SOD activity. In fact, SOD and CT have their activities reduced in toxic or pathological conditions associated with severe liver oxidative status. ${ }^{37}$ Thus, CT inactivation would lead to oxidative damage not only directly through $\mathrm{H}_{2} \mathrm{O}_{2}$ and its derivatives, but also indirectly through inhibition of SODs, hence leading to increased levels of superoxide radicals. Because of this and several other vicious cycles, it would be expected that the more oxidative damage the more ROS accumulation.

The results demonstrated that the GSH levels are decreased and GSH-Px activity is increased in OVX mice. Glutathione peroxidase is the major ROS scavenger, eliminating the $\mathrm{H}_{2} \mathrm{O}_{2}$ that escapes from the mitochondria and peroxisomes. As this enzyme consumes GSH, the elimination of hydrogen peroxide is another factor that contributes to the reductions in GSH levels observed in OVX mice, in which mitochondrial ROS generation is increased.

The activities of GSSG-Red, a GSH-restoring enzyme, and the G6PD were reduced in OVX mice, and this could also contribute to the lower levels of GSH in these animals. The reduction in the activity of G6PD can be attributed to estrogen deficiency. It has been known for a long time that G6PD is positively controlled by estrogen, ${ }^{38}$ and this has been further corroborated in studies performed in our laboratory. ${ }^{6,7}$

\section{Conclusion}

In conclusion, OVX mice fed a standard diet present reduced capacity of mitochondrial fatty acid oxidation along with dyslipidemia, alteration of liver redox state and high fasting glucose when maintained for a long time period after ovaries removal. Although the mechanisms underlying the reduced capacity of the livers to oxidize fatty acid in livers of OVX mice remain to be elucidated, it seems clear that the livers can develop more extensive metabolic disturbances under this endocrine status. Thus, it is plausible that livers from women in a long-term postmenopausal condition are more susceptible to metabolic dysfunctions, a possibility that deserves further experimental investigation.

\section{Contributions}

Oliveira M. C., Shimada L. B. C., Natali M. R. M., Iwamoto E. L. I. and Pagadigorria C. Z. S. contributed to conception and design of the study and the critical review of the intellectual content of the article. All authors approved of the version to be published.

\section{Conflicts of Interest}

The authors declare that there are no conflicts of interest.

\section{Acknowledgments}

This work was supported by grants from Coordenação de Aperfeiçoamento de Pessoal de Nível Superior (CAPES, in the Portuguese acronym)- CAPES/NUFFIC n.14/10.

\section{References}

1 Carr MC. The emergence of the metabolic syndrome with menopause. J Clin Endocrinol Metab 2003;88(06):2404-2411. Doi: 10.1210/jc.2003-030242

2 Day CP, James OF. Steatohepatitis: a tale of two "hits"? Gastroenterology 1998;114(04):842-845. Doi: 10.1016/S0016-5085 (98)70599-2

3 Paquette A, Wang D, Jankowski M, Gutkowska J, Lavoie JM. Effects of ovariectomy on PPAR $\alpha$, SREBP-1c, and SCD-1 gene expression in the rat liver. Menopause 2008;15(06):1169-1175. Doi: 10.1097/gme.0b013e31817b8159

4 Völzke H, Schwarz S, Baumeister SE, et al. Menopausal status and hepatic steatosis in a general female population. Gut 2007;56 (04):594-595. Doi: 10.1136/gut.2006.115345

5 Borrás C, Gambini J, López-Grueso R, Pallardó FV, Viña J. Direct antioxidant and protective effect of estradiol on isolated mitochondria. Biochim Biophys Acta 2010;1802(01):205-211

6 Campos LB, Gilglioni EH, Garcia RF, et al. Cimicifuga racemosa impairs fatty acid $\beta$-oxidation and induces oxidative stress in livers of ovariectomized rats with renovascular hypertension. Free Radic Biol Med 2012;53(04):680-689. Doi: 10.1016/j. freeradbiomed.2012.05.043

7 Gilglioni EH, Campos LB, Oliveira MC, et al. Beneficial effects of tibolone on blood pressure and liver redox status in ovariectomized rats with renovascular hypertension. J Gerontol A Biol Sci Med Sci 2013;68(05):510-520. Doi: 10.1093/gerona/gls210

8 Sankar P, Zachariah B, Vickneshwaran V, Jacob SE, Sridhar MG. Amelioration of oxidative stress and insulin resistance by soy isoflavones (from Glycine max) in ovariectomized Wistar rats fed with high fat diet: the molecular mechanisms. Exp Gerontol 2015; 63:67-75. Doi: 10.1016/j.exger.2015.02.001

9 Marí M, Morales A, Colell A, García-Ruiz C, Fernández-Checa JC. Mitochondrial glutathione, a key survival antioxidant. Antioxid Redox Signal 2009;11(11):2685-2700. Doi: 10.1089/ARS.2009.2695

10 Folch J, Lees M, Sloane Stanley GH. A simple method for the isolation and purification of total lipides from animal tissues. J Biol Chem 1957;226(01):497-509

11 Bracht A, Ishii-Iwamoto EL, Salgueiro-Pagadigorria CL. Técnicas de centrifugação e de fracionamento celular. In: Bracht A, IshiiIwamoto EL, orgs. Métodos de Laboratório em Bioquímica. São Paulo, SP: Manole; 2003:77-101

12 Natarajan SK, Eapen CE, Pullimood AB, Balasubramanian KA. Oxidative stress in experimental liver microvesicular steatosis: role of mitochondria and peroxisomes. J Gastroenterol Hepatol 2006;21 (08):1240-1249. Doi: 10.1111/j.1440-1746.2006.04313.x

13 Lowry OH, Rosebrough NJ, Farr AL, Randall RJ. Protein measurement with the Folin phenol reagent. J Biol Chem 1951;193(01): 265-275

14 Garland PB, Shepherd D, Nicholls DG, Yates DW, Light PA. Interactions between fatty acid oxidation and the tricarboxylic acid cycle. In: Lowestein JM, ed. Citric Acid Cycle: Control and Compartmentation. New York, NY: Marcel Dekker; 1969:163-212

15 Scholz R, Bucher T. Hemoglobin-free perfusion of rat liver. In: Chance B, Estabrook RW, Williamson JR, eds. Control of Energy Metabolism. New York, NY: Academic Press; 1965:393-414

16 Mellanby J, Williamson DH. Acetoacetate. In: Bergmeyer HU, ed. Methods of Enzymatic Analysis. New York, NY: Academic Press; 1974:1840-1843

17 Hissin PJ, Hilf R. A fluorometric method for determination of oxidized and reduced glutathione in tissues. Anal Biochem 1976; 74(01):214-226. Doi: 10.1016/0003-2697(76)90326-2 
18 Ohkawa H, Ohishi N, Yagi K. Assay for lipid peroxides in animal tissues by thiobarbituric acid reaction. Anal Biochem 1979;95 (02):351-358. Doi: 10.1016/0003-2697(79)90738-3

19 Berson A, De Beco V, Lettéron P, et al. Steatohepatitis-inducing drugs cause mitochondrial dysfunction and lipid peroxidation in rat hepatocytes. Gastroenterology 1998;114(04):764-774. Doi: 10.1016/S0016-5085(98)70590-6

20 Taguchi H, Ogura Y, Takanashi T, Hashizoe M, Honda Y. In vivo quantitation of peroxides in the vitreous humor by fluorophotometry. Invest Ophthalmol Vis Sci 1996;37(07):1444-1450

21 Aebi H. Catalase. In: Bergmeyer HU, ed. Methods of Enzymatic Analysis. New York, NY: Academic Press; 1974:673-690

22 Marklund S, Marklund G. Involvement of the superoxide anion radical in the autoxidation of pyrogallol and a convenient assay for superoxide dismutase. Eur J Biochem 1974;47(03):469-474. Doi: $10.1111 / \mathrm{j} .1432-1033.1974 . t b 03714 . x$

23 Paglia DE, Valentine WN. Studies on the quantitative and qualitative characterization of erythrocyte glutathione peroxidase. J Lab Clin Med 1967;70(01):158-169

24 Mize CE, Langdon RG. Hepatic glutathione reductase. I. Purification and general kinetic properties. J Biol Chem 1962;237:1589-1595

25 Tian WN, Pignatare JN, Stanton RC. Signal transduction proteins that associate with the platelet-derived growth factor (PDGF) receptor mediate the PDGF-induced release of glucose-6-phosphate dehydrogenase from permeabilized cells. J Biol Chem 1994; 269(20):14798-14805

26 Adams LA, Angulo P. Recent concepts in non-alcoholic fatty liver disease. Diabet Med 2005;22(09):1129-1133. Doi: 10.1111/ j.1464-5491.2005.01748

27 Martins-Maciel ER, Campos LB, Salgueiro-Pagadigorria CL, Bracht A, Ishii-Iwamoto EL. Raloxifene affects fatty acid oxidation in livers from ovariectomized rats by acting as a pro-oxidant agent. Toxicol Lett 2013;217(01):82-89. Doi: 10.1016/j.toxlet.2012.11.021

28 Franzoni AC, Amorim AM, Silva JVM, Storti JAP, Oliveira MC. Use of ursodeoxycholic acid on post-menopausal obesity, hepatic steatosis and plasma profile as an alternative treatment for hormone replacement therapy. Braz Arch Biol Technol 2015;58:898-904. Doi: 10.1590/S1516-89132015060310
29 de Oliveira MC, Gilglioni EH, de Boer BA, et al. Bile acid receptor agonists INT747 and INT777 decrease oestrogen deficiencyrelated postmenopausal obesity and hepatic steatosis in mice. Biochim Biophys Acta 2016;1862(11):2054-2062

30 Rogers NH, Perfield JW II, Strissel KJ, Obin MS, Greenberg AS. Reduced energy expenditure and increased inflammation are early events in the development of ovariectomy-induced obesity. Endocrinology 2009;150(05):2161-2168. Doi: 10.1210/en.2008-1405

31 Villanova N, Moscatiello S, Ramilli S, et al. Endothelial dysfunction and cardiovascular risk profile in nonalcoholic fatty liver disease. Hepatology 2005;42(02):473-480

32 Veech RL, Raijman L, Krebs HA. Equilibrium relations between the cytoplasmic adenine nucleotide system and nicotinamide-adenine nucleotide system in rat liver. Biochem J 1970;117(03): 499-503. Doi: 10.1042/bj1170499

33 Mannaerts GP, Debeer LJ, Thomas J, De Schepper PJ. Mitochondrial and peroxisomal fatty acid oxidation in liver homogenates and isolated hepatocytes from control and clofibrate-treated rats. J Biol Chem 1979;254(11):4585-4595

$34 \mathrm{Kim}$ YY, Kim SH, Oh S, et al. Increased fat due to estrogen deficiency induces bone loss by elevating monocyte chemoattractant protein-1 (MCP-1) production. Mol Cells 2010;29(03): 277-282. Doi: 10.1007/s10059-010-0027-x

35 Sanyal AJ, Campbell-Sargent C, Mirshahi F, et al. Nonalcoholic steatohepatitis: association of insulin resistance and mitochondrial abnormalities. Gastroenterology 2001;120(05):1183-1192. Doi: 10.1053/gast.2001.23256

36 Kowaltowski AJ, de Souza-Pinto NC, Castilho RF, Vercesi AE. Mitochondria and reactive oxygen species. Free Radic Biol Med 2009;47 (04):333-343. Doi: 10.1016/j.freeradbiomed.2009.05.004

37 Mohamed Sadek K. Antioxidant and immunostimulant effect of carica papaya linn. Aqueous extract in acrylamide intoxicated rats. Acta Inform Med 2012;20(03):180-185. Doi: 10.5455/ aim.2012.20.180-185

38 Ibim SEM, Randall R, Han P, Musey PI. Modulation of hepatic glucose-6-phosphate dehydrogenase activity in male and female rats by estrogen. Life Sci 1989;45(17):1559-1565. Doi: 10.1016/ 0024-3205(89)90422-0 